\title{
SOCIOEDUCAÇÃO: DA ONTOLOGIA À TELEOLOGIA - UMA AMBIGUIDADE TEÓRICA
}

\author{
SOCIO-EDUCATIONAL MEASURES: FROM ONTOLOGY TO TELEOLOGY - A \\ THEORETICAL AMBIGUITY
}

\author{
ERICA BABINI LAPA DO AMARAL MACHADO \\ Doutora em Direito pela Universidade Federal de Pernambuco (UFPE). \\ Professora de Direito Penal e Criminologia da Universidade Católica de Pernambuco (UNICAP). \\ ericababini@hotmail.com
}

\begin{abstract}
RESUMO
Trata-se de discussão teórica sobre o conceito de socioeducação, ponderando a sua natureza, reconhecida como criminal, devido à estrutura normativa e a consequência de uma prática de ato infracional, que em si é um fato ilícito. Não obstante a natureza (ontologia) criminal, não pode a medida socioeducativa ser confundida com a pena, posto que a socioeducação cumpre outras funções, devido à condição peculiar de desenvolvimento do adolescente em conflito com a lei. Por outro lado, os objetivos (teleologia) da socioeducação também precisam ser problematizados, especialmente ante a realidade neoliberal que enfrenta o conceito de educação. Com todas essas questões, a partir de uma revisão bibliográfica, medotologicamente orientada, restou evidente ambiguidades do instituto jurídico medida socioeducativa, cabendo, desse modo, enveredar esforços no sentido da construção da proposta de uma cidadania juvenil que independa da resposta estatal baseada em retribuição.
\end{abstract}

Palavras-chave: Socioeducação, pena, ontologia, teleologia.

\begin{abstract}
This is a theoretical discussion on the concept of socio-educational measures, considering its criminal nature, due to the normative structure and the consequence of an infractional act, which is by itself an illicit fact. Despite the criminal nature (ontology), the socio-educational measure can not be confounded with the punishment, because socio-education aims other purposes, on account of the peculiar condition of the teenager's development in conflict with the law. On the other hand, the objectives (teleology) of socio-education also have to be discussed, especially in light of the neoliberal reality that confronts the concept of education. So, by methodologically reviewing literature, this paper concluded that the legal institute of socio-educational measures has many ambiguities, and in face of it, it is important to creat mechanisms to bring up a youth citizenship that independs on the state's response based on retribution.
\end{abstract}

Keywords: Socio-educational measures, punishment, ontology, teleology.

\section{SUMÁRIO}

INTRODUÇÃO; 1 DA ONTOLOGIA PENAL À DIFERENÇA DA PENA: UMA COMPREENSÃO DA MEDIDA SOCIOEDUCATIVA DE INTERNAÇÃO; 1.1 Adolescente: um sujeito em construção; 1.2 A ontologia penal e a diferença da pena: investigando justificativas; 2 OS OBJETIVOS TELEOLÓGICOS: DA AMBIGUIDADE TEÓRICA A METODOLOGIAS IRREALIZÁVEIS - O QUE NÃO PODE SER A MEDIDA SOCIOEDUCATIVA; CONCLUSÃO; REFERÊNCIAS. 


\section{INTRODUÇÃO}

Em tempos de discussão sobre a redução da idade penal no Congresso Nacional, senso comum e política legislativa alinham-se na conclusão da necessidade de maior intervenção penal sobre adolescentes, posto alegarem não serem as medidas socioeducativas retributivas. No entanto, essa percepção, além de derivar do não conhecimento da realidade das medidas socioeducativas no país, deve-se à própria incapacidade de explicação do que é socioeducação.

Existem pouquíssimos debates sobre a natureza da medida socioeducativa. Diversos manuais sobre o Estatuto da Criança e do Adolescente não contemplam essa discussão, limitando-se às descrições sobre espécies e formas de aplicação ${ }^{1}$. Essa omissão, nos mecanismos de doutrinação dos operadores do Direito, somada à impermeabilização do Direito, que impede discussões interdisciplinares, bem como, o caráter eletivo da disciplina, na maioria dos bancos universitários; são fatores que auxiliam na alienação da operação desse sistema.

Antes, porém, de efetivamente adentrar no tema, o que se pode ter como certo é que não é possível equilibrar um modelo educativo no espaço judicial sem excluir parcelas de um ou de outro, afinal "a relação entre a pertinência jurídica e o ideal pedagógico não é simétrica"2. Legalmente, a finalidade pedagógica é o sustentáculo das medidas, tal como dispõe o art. 113 ao referendar o art. 100 do ECA; e três princípios condicionam responsabilização: o princípio da brevidade, enquanto limite cronológico; o da excepcionalidade, enquanto limite lógico do processo decisório; e o respeito à condição peculiar de pessoa em desenvolvimento, enquanto limite ontológico na decisão acerca da medida ${ }^{3}$.

Ou seja, o conjunto da legislação claramente prioriza a aplicação de medidas alternativas à privação de liberdade, o que pode ser percebido quantitativamente - quatro espécies de medidas em meio aberto (advertência, reparação de dano, prestação de serviço a comunidade e liberdade assistida) e duas em meio fechado (semiliberdade e internação). Em

\footnotetext{
1 Por exemplo, os manuais: CERQUEIRA, Thales Tácito de Pádua. Manual do Estatuto da Criança e do Adolescente: Teoria e Prática. 2 ed. São Paulo: Impetus, 2011; ISHIDA, Válter Kenji. Estatuto da Criança e do Adolescente. São Paulo: Atlas, 2014; NUCCl, Guilherme de Souza. Estatuto da Criança e do Adolescente Comentado. 2 ed. São Paulo: Forense, 2014; ELIAS, Roberto João. Comentários Ao Estatuto da Criança e do Adolescente. 4 ed. São Paulo: Saraiva, 2010.

2 KONZEN, Afonso Armando. Pertinência Socioeducativa: Reflexões sobre a natureza jurídica das medidas. Porto Alegre: Livraria do Advogado, 2005, p. 18.

${ }^{3}$ COSTA, Antônio Carlos Gomes da. In: CURY, Munir, et all (coord.). Estatuto da Criança e do Adolescente comentado: comentários jurídicos e sociais. 3 ed. São Paulo: Malheiros, 2000, p. 41.
} 
qualquer hipótese, todas condicionadas à ofensa ao bem jurídico por uma conduta ilícita (ato infracional).

Isto é, do ponto de vista da essência, a medida socioeducativa é uma sanção, especialmente porque só emerge após a prática de um ato ilícito. É uma reação estatal, inclusive com coerção física para sua aplicação, pois são unilaterais (não cabe ao adolescente querer cumprir ou não, tem que subordinar-se) e obrigatórias. Inclusive o artigo 112 do ECA é taxativo neste sentido: "verificada a prática do ato infracional, a autoridade competente poderá aplicar ao adolescente as seguintes medidas" [...].

O dispositivo legal segue orientação das Regras de Beijing, que estabelece no item 2.2 o seguinte: “b) infração é todo comportamento (ação ou omissão) penalizado com a lei, de acordo com o respectivo sistema jurídico; c) jovem infrator é aquele a quem se tenha imputado o cometimento de uma infração ou que seja considerado culpado do cometimento de uma infração"4.

Ante esses contextos, o que parece haver é uma confusão entre natureza da medida socioeducativa (ontologia) e os objetivos (teleologia) do instituto jurídico, uma desordem que leva a população ao desconhecimento da temática, cujo resultado é o incremento de punitivismos.

A preocupação de diferenciar a medida da pena (para o adulto) e por que fazê-la; e, ao menos, ponderar o que não pode ser a medida socioeducativa, ainda que não se possa, nesse exíguo espaço de texto, dizer o que pode sê-la, é premente; sobretudo nos dias atuais, em que existem cerca de 23.066 adolescentes em cumprimento de medida socioeducativa e há uma representatividade de $50 \%$ da população brasileira que concorda com a ideia de que "bandido bom é bandido morto" 5 .

Nesse sentido, a partir de revisão bibliográfica, única metodologia adotada no texto, no primeiro item será discutida a natureza da medida socioeducativa, buscando compreender a natureza responsabilizatória da resposta estatal a atos praticados por adolescentes e em seguida será discutida a diferenciação com a pena; bem como por que devem as respostas estatais serem diferentes para o adulto e para o adolescente.

No segundo item, os objetivos da medida, em sua capacidade teleológica, serão debatidos, para tentar se delinear, ao menos, o que não pode ser a medida socioeducativa.

\footnotetext{
${ }^{4}$ ONU. Regras Mínimas das Nações Unidas para a Administração da Justiça, da Infância e da Juventude. Regras Mínimas de Beijing. <http://www.crianca.caop.mp.pr.gov.br/arquivos/File/politica_socioeducativa/regras_minimas_beijing.p df>. Acesso em: 12 out. 2015.

${ }^{5}$ Fórum Brasileiro de Segurança Pública. 9 Anuário Brasileiro de Segurança Pública. São Paulo, 2015.
} 
Enfim, o objetivo do trabalho é trazer luzes à discussão sobre a socioeducação, buscando pensá-la em suas bases teóricas.

\section{DA ONTOLOGIA PENAL À DIFERENÇA DA PENA: UMA COMPREENSÃO DA MEDIDA SOCIOEDUCATIVA DE INTERNAÇÃO}

A ontologia diz respeito à natureza da medida socioeducativa e, como tal, é diferente da pena (em tese). Do ponto de vista histórico, sempre houve a tendência de negar o caráter sancionatório das medidas socioeducativas, posto que, agindo o Estado na tutela, e, portanto, em benefício do “menor”, não seria necessário garantias perante o poder punitivo do Estado, afinal retribuição não era o fim almejado. Pelo contrário, a medida seria sadia e nobre, por isso "eticamente sustentável”“. Ou seja, não tendo a medida caráter penal, nenhum controle de legalidade era necessário.

Trata-se de um período de concepção da Doutrina da Situação Irregular, um paradigma que tinha como proposição a “minimización formal del control para lograr el máximo de represión material"7.

Contudo, a partir da Doutrina da Proteção Integral, em que se acreditava vivenciar um "avance qualitativo [...] assistimos a la construcción de un nuevo derecho para la infancia y la adolescencia" 8 , dado o reconhecimento dos adolescentes como sujeito de direitos, e não mais objeto de tutela estatal ${ }^{9}$, opera-se um novo padrão de responsabilização da Criança e do Adolescente.

Isto é, a proteção especializada do sistema de crianças e adolescentes decorre da transição marcada pela migração do paradigma positivista para o humanitário, em que as liberdades e garantias constituíram consequência da evolução do Direito Internacional e dos Direitos Humanos no século XX e que definiram princípios que regem o sistema legal de proteção à criança e ao adolescente.

O sistema legal regente da criança e do adolescente estrutura-se em princípios que norteiam a aplicação da lei. A Convenção dos Direitos da Criança (CDC) acolhe a concepção de

\footnotetext{
${ }^{6}$ KONZEN, Afonso Armando. Pertinência Socioeducativa. Reflexões sobre a natureza judicial das medidas. Porto Alegre: Livraria do Advogado, 2005, p. 40.

7 GARCÍA MÉNDEZ, Emílio. Infância: de los derechos y de la justicia. 2 ed. Buenos Aires: Editores del Puerto, 2004, p. 37.

8 BARATTA, Alessandro. Elementos de um nuevo derecho para la infância y la adolescência, Capítulo criminológico, v. 23, n. 1. Maracaibo, enero/junio, 1995, p. 3.

${ }^{9}$ MENDÉZ, Emilio García. Infância e cidadania na América Latina. São Paulo: Hucitec, 1998.
} 
desenvolvimento integral da criança, reconhecendo-lhe absoluta prioridade, resguardando 0 melhor de seus interesses, obrigando os Estados a respeitar as responsabilidades, direitos e obrigações dos pais de prover a direção apropriada para o exercício dos direitos reconhecidos na Convenção ${ }^{10}$. Isto é, considerados agora sujeitos de direitos, crianças e adolescentes deixam de ser objetos passíveis de tutela da família, do Estado e da sociedade; saem da condição de objetos de direito para a de sujeitos que possuem direitos.

Como primeira providência, atendendo ao dispositivo da Convenção dos Direitos da Criança (art. 40. 3. $\mathrm{a}^{11}$ ), o ECA estabeleceu a divisão entre criança (até doze anos incompletos) e adolescentes (de 12 anos completos até dezoito anos incompletos), apresentando um sistema de responsabilização pelos atos infracionais praticados pelos adolescentes e a irresponsabilidade absoluta para as crianças. Ao lado dessa providência, está o princípio do interesse superior da criança, segundo o qual se coloca em primeiro plano a necessidade de concretização dos interesses maiores das crianças e adolescentes.

Nesse contexto, a Doutrina dirige-se a todas crianças ou adolescente, sem qualquer distinção, não se limitando à proteção e à vigilância, posto que promove e defende direitos ${ }^{12}$. Abandona o binômio compaixão-repressão, resolvendo questões sociais e psico-pedagógicas na esfera administrativa, na medida em que foi criada uma entidade específica para aplicação e execução de medidas de proteção (Conselho Tutelar). Além disso, estrutura a forma de responsabilização do adolescente em conflito com a lei com incidência de garantias penais e processuais.

Quer-se dizer, não obstante a construção de um sistema específico de proteção, a responsabilização penal se assenta, de modo que avulta a problemática: “Como construir um sistema de responsabilidade penal especial para pessoas menores de idade que não frustre 0 postulado da proteção especial?"13

$O$ fato é que se trata de um sistema de responsabilização penal, ainda que com nomes diferentes, e essa natureza é confirmada quando se tem que ela somente surge quando se há a confirmação da prática de um ato infracional, diferenciando-se das medidas especiais de

\footnotetext{
${ }^{10}$ DOLINGER, Jacob. Direito Internacional Privado: a criança no direito internacional privado. Rio de Janeiro: Renovar, 2003, p. 90.

${ }_{11}$ Os Estados Partes se comprometerão a: "O estabelecimento de uma idade mínima abaixo da qual se presume que as crianças não têm capacidade para infringir a lei penal;

${ }^{12}$ CILLERO BRUÑOL, Miguel. El Interés Superior del Niño en el Marco de la Convención Internacional sobre los Derechos del Niño. In: UNICEF, Justicia y derechos del niño. Santiago de Chile, 1999.

${ }^{13}$ BELOFF, Mary. Los Jóvens y el Delito: La responsabilidad es la clave. In: MÉNDEZ, Emilio García (org.). Infancia Y Democracia en la Argentina. La cuestión de la responsabilidad penal de los adolescentes. Buenos Aires: Del Signo, 2004, p. 31.
} 
proteção que se destinam aos sujeitos em situação de vulnerabilidade social. A perspectiva da responsabilização é evidenciada nos objetivos das medidas socioeducativas elencados pelo Sistema Nacional de Atendimento Socioeducativo (Sinase):

\begin{abstract}
Art. $1^{\circ}, \S 2 \underline{0}$ Entendem-se por medidas socioeducativas as previstas no art. 112 da Lei no 8.069, de 13 de julho de 1990 (Estatuto da Criança e do Adolescente), as quais têm por objetivos:

I - a responsabilização do adolescente quanto às consequências lesivas do ato infracional, sempre que possível incentivando a sua reparação;

II - a integração social do adolescente e a garantia de seus direitos individuais e sociais, por meio do cumprimento de seu plano individual de atendimento; e III - a desaprovação da conduta infracional, efetivando as disposições da sentença como parâmetro máximo de privação de liberdade ou restrição de direitos, observados os limites previstos em lei ${ }^{14}$.
\end{abstract}

Além disso, as regulamentações internacionais evidenciam o caráter penal da medida Regras Mínimas das Nações Unidas para a Administração da Justiça de Menores ou Regras de Beijing, as Regras Mínimas das Nações Unidas para os Jovens Privados de Liberdade e as Diretrizes das Nações Unidas para a Administração da Justiça Juvenil ou Diretrizes de Riad.

Apesar de todos esses esforços de superação de paradigmas, o que se tem é que "a história da infância é a história de seu controle" ${ }^{15}$, e nesse caso, não se pode perder de vista que a natureza criminal leva a essa reflexão pontuada por Edson Sêda ${ }^{16}$ :

Ah, os eufemistas. Uns por delicadeza, suavizam os termos para dizer coisas. Outros não ousam dizer o que pensam que deve ser dito [...] Quem foi privado de liberdade está preso. Então quais, quais seriam estes atos infracionais que podem até mesmo levar à prisão? Seriam atos infracionais ao regulamento da escola? Ao estatuto de um clube? À regras de etiqueta? Às ordens do pai e mãe? À arbitrariedade da polícia ou de outro agente, autoridade ou cidadão qualquer? Ao Código Civil? Parece que não é!

Do ponto de vista ontológico, resta clara a natureza criminal da medida socioeducativa, mas se assim o é, o que a diferencia da pena, e por que deve ser diferente?

\footnotetext{
${ }^{14}$ BRASIL. Lei 12.594. Brasília: Senado Federal, 2012 Disponível em: <http://www.planalto.gov.br/ccivil_03/_ato2011-2014/2012/lei/l12594.htm>. Acesso em: 08 ago. 2016.

${ }^{15}$ GARCÍA MENDÉZ, Emílio. Prehistoria e historia del control socio-penal de la infancia: política jurídica y derechos humanos En américa latina. In: Ser niño en America Latina. De las necessidades a los derechos. Galerna: Unicri, 1991.

${ }^{16}$ SÊDA, Edson. Os eufemistas e as crianças no Brasil. Rio de Janeiro: Adês, 1999, p. 1-16.
} 


\subsection{Adolescente: um sujeito em construção}

A Doutrina da Proteção Integral pactuou um sistema especializado para criança e adolescente, e aqui, no caso da responsabilização, não por meras razões de conveniência, mas por estar esse sujeito em processos de desenvolvimento de sua individualidade.

A adolescência é um processo centrado na lógica da separação-individuação, em que o adolescente deve separar-se dos objetos internalizados e descobrir objetos de amor e ódio extrafamiliares, expulsando a dimensão fantásmica atribuída ao longo da educação. Para outros, diferentemente, trata-se de uma crise, entendida como uma perturbação temporária dos mecanismos de regulação do sistema, seja devido a fatores socioculturais, seja devido a fatores biológicos ${ }^{17}$.

Em termos biológicos, a adolescência é um período específico de maturação de lutos, os quais representam perdas de personalidade e reconstrução de outras. 0 corpo e o esquema corporal (resultante intrapsíquica da realidade do sujeito, representação mental que o sujeito tem do seu próprio corpo como resultado de suas experiências) são entidades fundamentais para a compreensão deste processo.

As mudanças físicas se dão em três níveis reconhecidos pela puberdade: a) ativação dos hormônios gonadotróficos, responsáveis pela modificação sexual; b) secreção do hormônio com a produção de óvulos e espermatozóides; c) desenvolvimento das características sexuais primárias (aumento das genitálias) e secundárias (seios, cintura, quadril, pelos, voz).

Estas mudanças implicam o desenrolar dos lutos.

Luto do corpo infantil, em que o adolescente assiste passivamente uma série de modificações em sua estrutura, sentindo-se impotente. É a perda do corpo infantil com a mente ainda na infância, num processo de despersonificação. Esta perda leva à insegurança e ansiedade porque não se sabe o que está por vir.

Devido a isso, dá-se uma busca por situações estabilizadoras, dentre as quais a tendência grupal, em busca de uniformidade para propiciar segurança e estima pessoal. Para o grupo, transfere o adolescente grande parte da dependência, antes da estrutura familiar. É útil para as dissociações, projeções e identificações, como transição do mundo interno para o externo para conquistar a individuação adulta. A busca da identidade, pessoal e social, tarefa

${ }^{17}$ CAHN, Raymond. 0 adolescente na psicanálise: a aventura da subjetivação. Rio de Janeiro: Companhia de Freud, 1999, p. 18. 
maior da adolescência, é o sentimento subjetivo de unidade e continuidade pessoal, ao mesmo tempo específica do sujeito e reconhecida por todos, numa projeção de passado-futuro ${ }^{18}$.

0 adolescente combate em muitas fronteiras - de dentro para fora, seja entre o consciente e o inconsciente, seja entre o biológico e psíquico e social. Esta encruzilhada, em direção à realidade, dependerá de investimentos nas representações que o adolescente tem dos objetos externos e que este inflete em um sentido ou em outro. Este espaço transicional ganha contornos específicos quando nas sociedades atuais é desprovido de rituais de iniciação que o integram a seu lugar próprio nas crenças comuns do grupo, na sua família e nele mesmo, momento em que ele forja para si seu mito pessoal ${ }^{19}$.

Segundo o grau de confiabilidade ou ao contrário, da carência do objeto interno e externo, se dará a busca de dar sentido à vida, no encontrar seu lugar no socius, ou nas expressões patológicas, em sua distorção fetichista na drogadição, e nos acting. Neste último caso, tanto o constrangimento das configurações simbólicas onde foi aprisionado quanto a carência de respostas culturais the impõem um logro onde o adolescente se fechará para o mundo ${ }^{20}$.

Enfim, é uma multiplicidade e sucessões de ligamentos-desligamentos, onde a angústia da castração e a patologia da representação são protagonistas que faz o adolescer ser um momento específico da fase da vida.

O fato é que não existem muitos olhares referentes ao estudo da adolescência que levem em consideração o ponto de vista do adulto, cujo cerne é a resistência e ambivalência dos pais em aceitar o processo de crescimento. Na verdade, o que se tem é que "sob o disfarce da adolescência difícil está o de uma sociedade difícil, incompreensiva e hostil [...] razão pela qual a violência dos jovens não é mais do que a resposta à violência institucionalizada das forças da ordem familiar e social"21.

Por esta razão que a adolescência não deve ser vista como uma fase muito específica, que não é somente a passagem entre a puberdade e vida adulta. Este olhar é um adultomorfismo $^{22}$ que termina por estereotipar a adolescência $e$ individualmente os adolescentes, construindo-se raciocínios equivocados.

\footnotetext{
${ }^{18}$ CAHN, Raymond. O adolescente na psicanálise: a aventura da subjetivação. Rio de Janeiro: Companhia de Freud, 1999, p. 24.

${ }^{19}$ Ibid., p. 22.

${ }^{20}$ Ibid., p. 22.

${ }^{21}$ ABERASTURY, Arminda; KNOBEL, Maurício. Adolescência normal: um enfoque psicanalítico. 5 ed. Porto Alegre, 1986, p. 16.

22 Ibid., p. 26.
} 
Como a estabilização da personalidade passa por um grau de conduta patológica, é indispensável que se compreenda os conflitos interiores vivenciados, sobretudo as posturas defensivas devido à elaboração dos lutos já referidos. Colocar a adolescência unicamente como preparação para a vida adulta é determinar-lhe condicionamentos dos valores adultos, cuja projeção gera estereótipos.

Além dessas questões, os jovens marginalizados por vezes identificam-se com a criminalidade e com a prática de atos infracionais numa tentativa de tornarem-se visíveis socialmente, a fim de que possam garantir alguma existência social. Afinal, eles convivem com o drama da dificuldade de inserção no mercado de trabalho, a inclusão social que é frustrada, a precariedade de educação e profissionalização, vivências da grande maioria dos jovens brasileiros que se tornam autores de atos infracionais ${ }^{23}$.

Logo, é preciso oferecer lugar a essas crianças que não seja somente o de infrator ou de abandonado, mas antes da intervenção coercitiva.

\subsection{A ontologia penal e a diferença da pena: investigando justificativas}

Do ponto de vista ontológico, que diz respeito à natureza da medida, embora esta seja criminal, não pode ser pensada à luz das funções da pena, não somente por impertinência teórica, mas pela própria irrealização das funções penais. Em termos de prevenção geral, não é cabível, primeiro, porque não existe nenhuma certeza sobre o nexo causal entre o comportamento criminalizável e a pena, o que leva à reflexão de que a pena mais estabiliza e reproduz o universo criminal do que o extingue, como pretendia. Aliás, é uma ingenuidade crer que atos legislativos resolvem problemas sociais, econômicos, políticos, culturais... ${ }^{24}$ Segundo, porque o princípio da condição peculiar de desenvolvimento impede que os adolescentes sejam tratados como meio de atingir fins sociais ${ }^{25}$ para definições de mínimos éticos tidos como necessários para a convivência coletiva, tal como se presta a prevenção geral.

Considerando que o respeito à condição peculiar de desenvolvimento é direito fundamental, garantido ao adolescente que, nesta fase, vivencia estruturações da personalidade, não pode a prevenção geral prevalecer na medida socioeducativa.

\footnotetext{
${ }^{23}$ SOARES, L. E. Cabeça de Porco. Rio de Janeiro: Objetiva, 2005.

24 MELOSSI, Darío. Ideología y Derecho Penal. Garantismo Jurídico y criminologia crítica: ?Nuevas ideologías de la subordinacíon? Revista Nueva Doctrina Penal. Buenos Aires, p. 75-86, Del Porto Ed, 1996. ${ }^{25}$ OTERO, Juan Manuel. A hipocrisia e a dor no sistema de sanções do direito penal, Discursos Sediciosos, crime, direito e sociedade, Rio de Janeiro, 2007.
} 
No que tange à prevenção especial, a proposta barra com a necessidade de personalização dos adolescentes. A ressocialização é apresentada como um direito do condenado, o que no caso dos adolescentes está no art. 40.1 da CDC. É como se houvesse uma base utilitarista na aplicação da medida - a renúncia do castigo com garantia de redução da suposta periculosidade delitiva, no sentido de evitar a reincidência ${ }^{26}$.

Porém, para alguns doutrinadores, se fosse a prevenção especial que se sobrepusesse como fundamento da medida, teria que haver mais medidas em meio fechado do que em meio aberto para poder normalizar o comportamento, o que não é a realidade das medidas socioeducativas, dado que a proposta educativa implica saídas, assim como tempo reduzido (art. $37.1(\mathrm{CDC})^{27}$.

Mas mesmo que se tenha a idealização de que não se trata de prevenção especial, cujos problemas de legitimação residem na pretensão de modificar a personalidade por meio da força, uma ofensa à dignidade da pessoa humana, disto não se pode efetivamente afastar-se, posto que o mandato que autoriza o Estado a educar os adolescentes fala em educação pedagógica através da segregação. No mínimo, uma contradição, que é em si a contradição de qualquer espécie de encarceramento.

Se se admite a questão da prevenção especial isso nada tem a ver com o direito à educação, e sim com o direito à autonomia moral, dignidade, livre desenvolvimento da personalidade, de modo que o adolescente deve consentir ao tratamento reeducador, uma exigência fundamental ${ }^{28}$.

É por isto que, para alguns autores, é mesmo o fim preventivo-especial que configura o papel central de um Direito Penal do adolescente, distinguindo-o do procedimento do adulto ${ }^{29}$. No entanto, esta abordagem é vinculada a um sistema de responsabilização alemão, em que o enfoque no controle social é o marco de uma política criminal de exigência de conformidade com o comportamento legal.

É certo que no século XX boa parte dos sistemas de justiça juvenil se inspirou no ideal socioeducativo do Tribunal de Menores de Chicago, um dos primeiros da história, tendo formas alternativas - diversions - de possibilidades concretas de ideais ressocializadores, despojando-se

${ }^{26}$ COUSO, Jaime. Principio educativo y (re) socialización en el derecho penal juvenile. In: UNICEF. Justicia y derechos del niño. $\mathrm{n}$ 8. Chile, 2006.

${ }_{27}$ Ibid.

${ }^{28}$ ROXIN, Claus. Estudos de Direito Penal. 2 ed. Rio de Janeiro: Renovar, 2008.

${ }^{29}$ ALBRECHT, El Derecho penal de menores, traducción de la primera edición alemana por Bustos Ramírez, Barcelona, 1990, p. 108. 
de práticas dissocializadoras e estigmatizantes que levaram ao fracasso a primeira experiência histórica neste sentido ${ }^{30}$.

Porém, houve fatores estruturais, culturais, econômicos e sociais que possibilitaram a solidificação da criminologia correcionalista e o engendramento do previdenciarismo penal, marcado no período do Estado de bem-estar-social. Nos Estados Unidos e Grã-Bretanha, onde o paradigma correcionalista teve grande profusão, existia uma estrutura específica de relações de classe, mercado de trabalho, políticas econômicas e interação entre as instituições, com prosperidade econômica, expansão industrial e baixo nível de desemprego, além de uma rede de seguridade social que fazia com que a inclusão do indivíduo no tecido social se apresentasse como a mais adequada missão estatal ${ }^{31}$. Uma realidade desde logo incompatível com a brasileira que sequer viveu este modelo de welfare state, quando muito, uma industrialização tardia.

No entanto, como se tratava o Sistema de Justiça Criminal de objeto de estudos de especialistas e técnicos, jamais assunto de política ou do senso comum, dada a confiança e credibilidade dos operadores, enquanto não fosse investigado e sua dinâmica interna compreendida pelo público, o poder dos técnicos estava garantido e as críticas não emergiriam.

De tão disseminada a especificação do tema na prática social, constituindo mesmo um tabu, não havia qualquer ameaça à racionalidade penalógica, restando afastadas práticas tão comuns do cotidiano atual - o apelo implacável à condenação, a vingança da vítima, a revolta pública, a mercantilização midiática da notícia e apropriação político-eleitoral do tema.

Entretanto, com a crise das fontes ideológicas do Estado de bem-estar, também começam a ruir seus elementos e, neste sentido, a prática penitenciária passou a ser denunciada como violadora dos direitos de liberdade, resumida em definições como uma política paternalista e hipócrita, tal como definiu o relatório Struggle for Justice, do Partido Trabalhista; primeiro documento a evidenciar o Estado disciplinador, regulador e normalizador. Em seguida (1974) essas conclusões foram confirmadas com provas empíricas no artigo de Robert Martinson What Works? ${ }^{32}$.

Todo esse arcabouço foi auxiliado também por uma disputa de poder que não pode ser descuidada; porquanto, ao passo que os técnicos da criminologia oficial estavam vinculados ao

\footnotetext{
${ }^{30}$ COUSO, Jaime. Principio educativo y (re) socialización en el derecho penal juvenile. In: UNICEF. Justicia y derechos del niño. $\mathrm{n}$ 8. Chile, 2006.

${ }_{31}$ GARLAD, David. A cultura do controle. Crime e ordem social na sociedade contemporânea. Rio de Janeiro: Revan, 2008.

32 MARTINSON, Robert. What Works? - questions and answers about prison reform. Disponível em < <http://www.nationalaffairs.com/doclib/20080527_197403502whatworksquestionsandanswersaboutprison reformrobertmartinson.pdf >. Acesso em: 04 ago. 2016.
} 
governo, com salários e prestígio garantidos, os novos criminólogos estudavam o mesmo objeto, mas não tinham aquele quadro assegurado. Pelo contrário, as autonomias universitárias começavam a ser construídas e assim precisavam de espaço para apresentar seus resultados "talvez tenha sido por isso que o controle, e não o crime - tido como normatizado - foi o foco central da nova criminologia" 33 .

Daí em diante, dado os resultados negativos das pesquisas e as crescentes taxas de criminalidade, associada à reação despreocupada do novo marco criminológico com finalidades de governo, o paradigma da prevenção especial passou a ruir. Porém, ao se levar em consideração o caráter dependente e marginal da América Latina, que recebe as diretrizes dos países centrais através de suas elites, como se aqueles fossem conhecimento de vanguarda, importando-os acriticamente, conclui-se que este paradigma apesar de já desfalcado, ainda é presente no país e em muitas discussões criminológicas ${ }^{34}$.

Essa discussão foi realizada para contextualizar que o caráter pedagógico das medidas socioeducativas vincula-se ao paradigma correcionalista e isso, por tudo que foi explanado, além de inexequível, acomoda um caráter ambíguo. Essa afirmação pode ser identificada na legislação que afirma que a liberação da medida socioeducativa da internação está condicionada "pela realização de sua finalidade" (art. 46, II, da Lei 12.594/12 - Lei do Sinase), sem definir qual seja.

Para além das falências da prevenção especial apontadas, outro ponto relevantíssimo é a lógica do less elegibility, princípio fundamentador da punição, segundo o qual a condição de vida no regime carcerário deve ser sempre mais inferior do que goza o mais baixo estrato social da sociedade livre, fundamento discutido por Rush e Kishemmer ${ }^{35}$.

A perspectiva da menor elegibilidade é um raciocínio de economicidade do sistema punitivo, em que a política penal no capitalismo cumpre a função de desincentivo, o repúdio ao trabalho, forçando que aqueles que estão no estágio de vagabundagem aceitem forçosamente as condições opressivas do trabalho mal remunerado e explorado da indústria capitalista. "Por isto

\footnotetext{
${ }^{33}$ GARLAD, David. A cultura do controle. Crime e ordem social na sociedade contemporânea. Rio de Janeiro: Revan, 2008.

${ }_{34}$ Lola A. de Castro, fazendo uma análise do Simpósio Internacional de Criminologia em Estocolmo diagnosticou a "insistência do paradigma etiológico" nas investigações criminológicas, desde a área da genética, com estudos no DNA até a alimentação, com a hipótese de prevenção de homicídios a partir da nutrição com base em Omega 3, dada a redução da deterioração cerebral. CASTRO, Lola Aniyar. 0 regresso triunfante de Darwin e Lombroso: as diferenças humanas na Criminologia dos países de língua inglesa anos Simpósios Internacionais de Criminologia de Estocolmo. Discursos Sediciosos. Crime, direitos e sociedade. Ano 15, n. 17/18, p. 163-174,1 e 2 semestres, Rio de Janeiro, Revan, 2010.

${ }^{35}$ RUSCHE, George; KIRCHHEIMER, Otto. Pena y estructura social. Bogotá: Temis, 1984.
} 
os níveis de reclusão e as condições de encarceramento oscilam de acordo com a menor ou maior disponibilidade (e valor) da força de trabalho." 36

O pior é que a sobreposição da função simbólica (universos políticos do discurso que se legitima pela representação do que promete, formando consenso social) à instrumental (objetivos úteis da pena) permite a prevalência histórica de determinados tipos de castigo devido à interiorização da questão criminal, o que por sua vez legitima novas formas de castigo.

Nesse entre jogo, a práxis emancipatória, assumida pelo Estado, não avança. Em nome da segurança e da prevenção, da função simbólica, da redução dos riscos e do acesso ao mercado, o que se tem, instrumentalmente, é a marginalização e a seleção de categorias sociais de riscos, destinatárias do controle social, no sentido da imposição de uma less elegibility como meio extremo de forçar os adolescentes a aceitarem condições de vida cada vez mais drásticas.

Enfim, a natureza da medida é necessariamente punitiva e a punição deve ser pensada enquanto uma instituição social que condensa práticas rotineiras das relações sociais e culturais, ajudando a "definir a natureza da nossa sociedade, os tipos de relação que a compõem e as formas de vida que são possíveis e desejáveis de serem conduzidas nesta sociedade" 37 .

$\mathrm{Na}$ relação interativa existente entre pena e cultura, categorias são produzidas, comunicando sentidos de poder, autoridade, normalidade e moralidade - são esses conteúdos que precisam ser vergastados no cotidiano da medida socioeducativa de internação. Aliás,

Si una certa visión eufemística de la realiade se encuentra presente en las prácticas de privación de liberdade en el mundo de los adultos (producir la reinserción social por meio de práticas que constituyen su más absoluta negació), en el caso de la infancia-adolescencia esta visión se encuentra exacerbada has ta sus últimas consecuencias ${ }^{38}$.

Feitas essas considerações, reconhece-se que a medida socioeducativa tem natureza criminal, mas devido à condição peculiar de desenvolvimento do adolescente, não pode ser confundida com a pena. Isso significa que não cabe à medida retribuir nem pautar-se na prevenção geral e especial.

Diante disso, insta questionar: qual função deve a medida socioeducativa cumprir? Sigase a diante.

\footnotetext{
${ }^{36}$ Ibid., p. 3.

${ }^{37}$ GARLAD, David. A cultura do controle. Crime e ordem social na sociedade contemporânea. Rio de Janeiro: Revan, 2008, p. 287.

${ }^{38}$ GARCÍA MÉNDEZ, Emílio. Infância: de los derechos y de la justicia. 2 ed. Buenos Aires: Editores del Puerto, 2004, p. 31.
} 


\section{OS OBJETIVOS TELEOLÓGICOS: DA AMBIGUIDADE TEÓRICA A METODOLOGIAS IRREALIZÁVEIS - O QUE NÃO PODE SER A MEDIDA SOCIOEDUCATIVA}

Do ponto de vista teleológico, o conceito de socioeducação pode parecer redundante posto que toda prática educativa pressupõe que seja social. Porém, é importante ponderar sobre qual o conceito de educação se partilha.

Em um primeiro nível, educação se associa à ideia de transmissão de conhecimento. É um conceito da educação formal, no qual está embutido relações de poder, vez que o que vai ser transmitido depende de uma seleção, classificação e distribuição de como o conhecimento será transmitido. Daqui surge o primeiro questionamento, porque a depender da estruturação dos currículos (atividades que serão desempenhadas pelos adolescentes) haverá maior ou menor inserção democrática, em que os educandos terão (ou não) mais espaços para serem criativos e autônomos ${ }^{39}$.

Contudo, não é dessa educação que trata o fundamento da medida socioeducativa. A referência é tão múltipla que "dificilmente é possível identificar-se elementos comuns entre os tipos de educação resultante de cada caracterização" ${ }^{40}$. Em outros termos, a terminologia socioeducação é utilizada para diferenciar de educação escolar geral e educação profissional. 0 conceito vincula-se à preparação do sujeito para a vida em sociedade ${ }^{41}$, apesar de existir quem defenda $^{42}$ que cabe à socioeducação preparar o jovem para o convívio social, desenvolvendo seu potencial de ser e conviver, razão pela qual a socioeducação inserir-se-ia perfeitamente no conceito de educação formal: “O objetivo é oferecer uma formação adaptativa, embora se fale em cidadania, autonomia e criticidade" ${ }^{43}$.

Desde aqui se percebe algumas incongruências. Mas antes de adentrar nessas ambiguidades, é de se reconhecer evidente que, do ponto de vista metodológico, não há uma

\footnotetext{
${ }^{39}$ BERNSTEIN, Basil. Clasificacion y enmarcacion del conocimiento educativo. Class, Codes and control, Vol. 1 Towards a Theory of Educational Transmissions London: Routledge and Kegan Paul. 1974.

40 COUSO SALAS, Jaime. Problemas teóricos y prácticos del principio de separación de medidas y programas, entre la vía penal-juvenil y la vía de protección especial de derechos. In: Justicia y Derechos del niño. Santiago: UNICEF, 1999, p. 91.

${ }^{41}$ GURAKH, Soeli Andrea. A socioeducação na dinâmica de afirmação dos direitos da criança e do adolescente no Brasil. Emancipação, 10 (1), p. 351-359, Ponta Grossa, 2010.

42 COSTA, Antônio Carlos Gomes (coord). Parâmetros para a formação do socioeducador. Uma proposta inicial para a reflexão e debate. Brasília: Secretaria Especial de Direitos Humanos, 2006, p. 15.

${ }^{43}$ GALUCH, Maria Terezinha Bellanda. Reflexões sobre a organização do ensino e Formação no context das relações sociais de produção. Revista Internacional d'Humanitats, Universitat Autònoma de Barcelona, $n$. 21, jan-jun, 2011, p. 65.
} 
teoria que fundamente a socioeducação e the dê organicidade. 0 que existe são diversos enfoques e abordagens teóricas (da pedagogia, da sociologia e da psicologia), somados a parâmetros normativos.

\begin{abstract}
Sem nenhum exagero, podemos afirmar que o trabalho social e educativo dirigido às crianças e jovens em situação de especial dificuldade (principalmente os adolescentes infratores) se encontra entre nós num estágio pré-pedagógico. $\mathrm{Na}$ área do oficialismo (segurança pública, justiça e bem-estar do menor) predominam ainda concepções correcionais repressivas herdadas do passado autoritário. Conferir cidadania pedagógica ao trabalho social e educativo dirigido ao adolescente infrator e a outros grupos em situação de risco é, pois, uma tarefa urgente e necessária ${ }^{44}$.
\end{abstract}

Do ponto de vista metodológico, o conceito de socioeducação é marcado pela ideia da construção e educação para uma vida em sociedade. Educação que diz respeito à formação dos sujeitos sociais, que se dá pela apreensão de conhecimentos e formas de sociabilidade. É a apreensão de conteúdos sociais já construídos, posto que aprender a pensar e agir em sociedade depende da compreensão sócio-histórica dos sujeitos e das condições nas quais ele se realiza. Daí porque emergem práticas sociais, tradições, costumes... ${ }^{45}$ Trata-se de uma educação para a devolução da dignidade, "uma alternativa à educação formal para qualquer tipo de adolescente. Uma educação não discursiva, uma educação pelo trabalho" ${ }^{46}$.

Essa é a educação a que se refere a pedagogia com o ideal de emancipação e desenvolvimento da personalidade, a partir da autonomia e da participação, que significa considerar a plena subjetividade do adolescente ${ }^{47}$, o que parece conflitar com as propostas, inclusive em termos físicos, da estrutura socioeducativa a que se refere o Sinase.

A socioeducação é o parâmetro pedagógico das ações vinculadas aos adolescentes em conflito com a lei, a qual é alcançada pela execução das propostas do Sinase. Neste ponto, alguns elementos devem ser levados em conta - a direção política e as referências éticas.

O Sinase passa a ser a ferramenta indispensável para consolidar a travessia da doutrina da situação irregular para a doutrina da proteção integral. Em seu bojo, tem como instrumento o

\footnotetext{
${ }^{44}$ COSTA, Antônio Carlos Gomes da. Aventura Pedagógica. Caminhos e descaminhos de uma ação socioeducativa. São Paulo: Columbus Cultural Editoria, 1990, p. 38.

${ }_{45}$ MOREIRA, Celeste Anunciata Baptista Dias. Socioeducação e as medidas socioeducativas. In: FREIRE, Silene de Morais (Org.) Anais do IV Seminário Internacional de Direitos Humanos, violência e pobreza: a situação das crianças e adolescentes na América Latina hoje. Rio de Janeiro: Ed. Rede Sírius/UERJ, 2012.

${ }^{46}$ COSTA, Antônio Carlos Gomes da. Aventura Pedagógica. Caminhos e descaminhos de uma ação socioeducativa. São Paulo: Columbus Cultural Editorial, 1990, p. 145.

47 COUSO, Jaime. Principio educativo y (re) socialización en el derecho penal juvenile. In: UNICEF. Justicia y derechos del niño. n 8. Chile, 2006.
} 
Plano Individual de Atendimento - PIA, ferramenta pedagógica que gera a modalidade socioeducativa. O documento é pactuado pela instituição com o adolescente e a família no sentido do investimento para o rompimento da violência.

Do ponto de vista político, a proposta surge na década de 1990, em que entidades sociais da defesa dos direitos das crianças e adolescentes fomentaram discussões sobre o modelo de atendimento, dado o esgotamento da Fundação Estadual para o Bem Estar do Menor (FEBEM) na década de 70 com violações de direitos, rebeliões e motins.

Assim, a Associação Brasileira de Magistrados e Promotores da Infância e Juventude junto ao Fórum Nacional das Organizações Governamentais de Atendimento à Criança e ao Adolescente (Fonocriad) indicaram a necessidade de uma revisão da problemática, elaborando documento em 2004 que foi normatizado pela Secretaria Especial de Direitos Humanos em conjunto com o Conselho Nacional dos Direitos da Criança (Conanda) e a UNICEF.

Em 2006, esse documento apresentou os parâmetros de atendimento socioeducativo por meio da resolução 119, de 11 de dezembro de 2006, do Conanda, apesar de ser pouco adotado por juízes da infância e juventude. A pretensão era reverter a tendência crescente de internação, visando afastar o histórico processo de socioeducação, marcado por práticas com vistas à adequação dos sujeitos aos padrões hegemônicos de sociedade, adaptando os indivíduos às referências conservadoras e hierarquizadas ${ }^{48}$.

Sem dúvida, o Sinase é um grande avanço, porque coloca como princípio os direitos humanos, interligando políticas públicas através do sistema de garantias, com orientações éticas de base pedagógica como diretrizes para a proteção social do adolescente. O Sinase é destinado a realizar a inclusão do adolescente quanto ao exercício de seus direitos de cidadania, e por isso dialoga, obrigatoriamente, com as demais políticas públicas e sociais: educação, segurança pública e justiça, assistência social, saúde, cultura, esporte e lazer, entre outros.

A formulação das políticas socioeducativas em meio fechado de atribuição dos Estados e consequentemente dos Conselhos Estaduais dos Direitos da Criança e do Adolescente, deve observar como norma infralegal, de caráter geral, o artigo $2^{\circ}$ da Resolução n 46 de 1996 do CONANDA: “Em cada Estado da Federação haverá uma distribuição regionalizada de unidades de internação".

A regionalização das medidas privativas de liberdade - internação e semiliberdade implica o planejamento para a construção de unidades de internação e casas de semiliberdade

${ }^{48}$ MOREIRA, Celeste Anunciata Baptista Dias. Socioeducação e as medidas socioeducativas. In: FREIRE, Silene de Morais (Org.) Anais do IV Seminário Internacional de Direitos Humanos, violência e pobreza: a situação das crianças e adolescentes na América Latina hoje. Rio de Janeiro: Ed. Rede Sírius/UERJ, 2012. 
conforme as demandas que se apresentem por regiões, favorecendo, deste modo, a proximidade com os domicílios dos adolescentes inseridos nos respectivos programas ${ }^{49}$.

Nesse sentido, o Sinase passa a ser a ferramenta indispensável para consolidar a travessia da doutrina da situação irregular para a doutrina da proteção integral, no qual o PIA é o instrumento que viabiliza esse processo. O documento deve contemplar regras objetivas e claras para que o adolescente possa ter conhecimento das atividades que deve realizar para garantir seu progresso no confinamento da instituição. O plano também "vincula os educadores, técnicos e executores de medidas a atuarem junto a outras instâncias do poder público e mesmo entidades não-governamentais para o oferecimento dos serviços que o caso concreto demanda" ${ }^{50}$.

Neste sentido, a equipe deve se organizar para observar o comportamento do adolescente e incentivá-lo a interesses novos, ampliando o sentido de sua existência, sem que seja reduzido ao acompanhamento judicial de prazos como a única finalidade, o que configuraria distorções que aparecem na prática profissional, sem garantir nenhuma transformação da realidade dos adolescentes ${ }^{51}$.

A exigência do PIA como instrumento individualizador da execução da medida socioeducativa será fundamental para sua eficácia, pois através dele serão estabelecidas as metas e as atividades a que o adolescente estará submetido no cumprimento da medida socioeducativa aplicada pelo Poder Judiciário, tudo isso com o monitoramento do Juiz da Infância e Juventude, com a efetiva fiscalização do Ministério Público e do Defensor do representado. Por ter elementos objetivos, o PIA possibilita a avaliação objetiva sobre o cumprimento da medida, evitando que sejam considerados apenas aspectos subjetivos no momento de sua reavaliação.

É de se ter em mente que os parâmetros socioeducativos baseiam-se no conceito de educação que está no artigo $1^{\circ}$ da Lei de Diretrizes e Bases: “A educação abrange os processos formativos que se desenvolvem na vida familiar, na convivência humana, no trabalho, nas

\footnotetext{
49 SPOSATO, Karyna. Guia Teórico e prático das medidas socioeducativas. ILANUD/UNICEF. Brasília, 2004.

50 Ibid.

${ }^{51}$ MOREIRA, Celeste Anunciata Baptista Dias. Socioeducação e as medidas socioeducativas. In: FREIRE, Silene de Morais (Org.) Anais do IV Seminário Internacional de Direitos Humanos, violência e pobreza: a situação das crianças e adolescentes na América Latina hoje. Rio de Janeiro: Ed. Rede Sírius/UERJ, 2012.
} 
instituições de ensino e pesquisa, nos movimentos sociais e organizações da sociedade civil e nas manifestações culturais" 52 .

Ou seja, a metodologia é voltada para o mundo do trabalho, sem qualquer aproximação com o real, em detrimento de uma formação pautada no desenvolvimento humano pela via do acesso à cultura e ao conhecimento, em que o desenvolvimento de valores, atitudes e habilidades está em sintonia com uma formação adaptativa. Essa é a proposta internacional da Unicef para a educação.

Essa orientação ao mundo para a educação deriva de uma metamorfose pedagógica que se deve à ciência ter se transformado rapidamente em força produtiva, dado que o conhecimento se tornou vital para processo de acúmulo de capital, no contexto da produção capitalista. Nesse sentido a perspectiva é a formação de um trabalhador ilustrado possuidor de altos níveis de escolaridade.

A questão pedagógica na adolescência também abarca a inclusão digital com Tecnologias da Informação. A geração dos conhecidos por "nativos digitais", os nascidos pouco depois de 1980, tem a tecnologia como aliada imprescindível para o desenvolvimento. Essa geração compartilha uma cultura global comum por meio da tecnologia digital, cuja experiência é trocada por tecnologias da informação e com interação. No entanto, nem todos os adolescentes têm acesso a essas ferramentas, especialmente os adolescentes marginalizados socialmente, sobretudo aqueles em situação de conflito com a lei.

0 acesso a essas ferramentas naturalmente tem que superar algumas barreiras, como o acesso básico às tecnologias, à infraestrutura, especialmente eletricidade, à aquisição de habilidades e à compreensão sobre a forma de navegação do mundo on-line. Trata-se do que se tem denominado alfabetização digital - capacidade de navegar em um mundo digital - e que muitos adolescentes ainda não têm acesso, especialmente os privados de liberdade, e cujo déficit implicará dificuldades sociais, técnicas e de aprendizagem numa economia global conectada às redes.

Os benefícios de tecnologias digitais de grande alcance vão além da aprendizagem: promovem a criatividade, o empreendedorismo e o ativismo. Adolescentes e jovens utilizam essas tecnologias para expressar-se por meio da gravação em vídeo, em áudio e jogos. Estão criando movimentos políticos estimulantes, grupos de vigilância e novas formas de organização que combinam atividades dentro e fora da internet. À medida que se tornam adultos, alguns

\footnotetext{
${ }^{52}$ BRASIL. Lei 9.394. Brasília: Senado Federal: 1996. Disponível em: <http://www.planalto.gov.br/ccivil_03/Leis/L9394.htm>. Acesso em: 08 ago. 2016.
} 
deles estão criando novos negócios e novas tecnologias que geram empregos e oportunidades. Educam-se mutuamente enquanto constroem o ciberespaço global ${ }^{53}$.

Essa realidade neoliberal tem a lógica pedagógica do neoprodutivismo, a qual tem no indivíduo, e não mais no Estado, a responsabilidade pela preparação da mão de obra com capacitação para o trabalho e desenvolvimento de meios de competitividade. Trata-se de uma pedagogia de cunho neoliberal, em que tudo é voltado à acumulação de capital. A educação é mercadoria, razão pela qual tudo é organizado em torno da exploração do trabalho, cuja aprendizagem tem ênfase no individualismo, na competitividade e na profissionalização. Por outro lado, nas relações de trabalho a flexibilização das atribuições, a competitividade e a necessidade de aprender a aprender para a empregabilidade passam a ser características do processo produtivo.

É a pedagogia das competências que implica uma adaptação dos indivíduos ao meio, exigindo comportamentos flexíveis ante condições objetivas adversas. É uma forma de conduzir o indivíduo às adaptações ao mundo do trabalho e não a sua automização, atendendo ao deslocamento provocado pelo capitalismo de qualificação das competências. A educação passa a ter as mesmas necessidades do mundo empresarial, desprezando as dimensões sociais e históricas do processo educativo ${ }^{54}$.

Ou seja, a pedagogia das competências exige dos sujeitos criatividade, novas habilidades e autonomia ante aos parâmetros tecnológicos, de modo que as questões sociais de raça, classe, etnia e gênero são colocadas como coadjuvantes. Por essa razão, o conteúdo educacional é volátil e utilitarista, associando o ensino às questões práticas do cotidiano. É a educação a serviço da lógica de produção vigente. Tudo é funcional à doutrina neoliberal ${ }^{55}$.

$\mathrm{Na}$ medida em que somente as habilidades técnicas que são objeto de preocupação, e não a compreensão da realidade circunscrevente, está-se diante de uma contradição de base metodológica. E é o que parece em termos do Sinase.

Pois, somente a compreensão das realidades sociais e suas adversidades, o que se adquire por meio de questionamentos e enfrentamentos das culturas, é que permite a

\footnotetext{
53 UNICEF - Fundo das Nações Unidas para a Infância. Relatório. Situação Mundial da Infância. Adolescência, uma fase de oportunidades, 2011, p. 15.

${ }^{54}$ FERRETI, Celso João. A pedagogia das competências: autonomia ou adaptação? Educação Social, Campinas, v. 23, n. 81, p. 299-306, dez, 2002.

${ }_{55}$ MOREIRA, Celeste Anunciata Baptista Dias. Socioeducação e as medidas socioeducativas. In: FREIRE, Silene de Morais (Org.) Anais do IV Seminário Internacional de Direitos Humanos, violência e pobreza: a situação das crianças e adolescentes na América Latina hoje. Rio de Janeiro: Ed. Rede Sírius/UERJ, 2012.
} 
emancipação do sujeito, e não o adestramento em habilidades e ferramentas técnicas, em que o sujeito apenas assimila a ordem, sem ponderar se a ela quer se adequar.

$\mathrm{Na}$ perspectiva educacional, são as apropriações dos bens culturais, acumulados historicamente, que tornam o homem, homem. De modo que é possível se questionar: como falar em formação sem acesso a isto? Não basta somente repassar valores, é preciso desenvolver faculdades, por isso que não se pode falar em cidadania e inclusão sem que o sujeito tenha consciência do que venha a ser isto ${ }^{56}$.

Objetivos altamente questionáveis na realidade brasileira, "por não estar em condições de garantir à população em geral o acesso aos bens culturais sociais e econômicos que poderiam garantir-lhe os benefícios decorrentes de sua pertença a uma sociedade afluente" ${ }^{57}$. E aqui reside uma fraude, pois afinal todas estas potencializações promovidas pela perspectiva educacional se adequam à realidade neoliberal que tem a educação como mercadoria, mas não à realidade brasileira.

Ou seja, a prioridade das formas de pensar e agir guiadas por valores, e não a emancipação humana, a capacidade de adaptação e não a compreensão das contradições sociais, tudo como forma de manter a coesão social - são as ênfases que guiam a orientação da educação brasileira e que fundamentam as propostas do Sinase. Isso significa ponderar: "Como é possível construir práticas socioeducativas sem uma efetiva produção de crítica para a realidade? Como contribuir para a emancipação de sujeitos sem reconhecer o movimento do real e as disputas de classe, gênero, raça e etnia presentes na sociedade?" 58 Não se emancipa com despolitização dos direitos nas políticas públicas.

Enfim, em termos de objetivos é possível identificar algumas promessas inverídicas da pretensão socioeducativa, a ponto de beirar uma fraude, no sentido de que a promessa existe (inviável de ser executada) para justificar a ação desmedida de práticas segregatórias.

É interessante porque no mesmo relatório Delors, não obstante à pedagogia das competências, a educação tem por objetivo criar vínculos sociais entre pessoas, em que o respeito ao pluralismo é eixo fundamental, tentando adaptar-se ao desafio moderno em que a educação é chamada para fazer da diversidade um fator positivo de compreensão mútua entre

\footnotetext{
${ }^{56}$ GALUCH, Maria Terezinha Bellanda. Reflexões sobre a organização do ensino e Formação no contexto das relações sociais de produção. Revista Internacional d'Humanitats, Universitat Autònoma de Barcelona, n. 21, jan-jun, 2011.

${ }^{57}$ FERRETI, Celso João. A pedagogia das competências: autonomia ou adaptação? Educação Social, Campinas, v. 23, n. 81, p. 299-306, dez, 2002.

${ }^{58}$ MOREIRA, Celeste Anunciata Baptista Dias. Socioeducação e as medidas socioeducativas. In: FREIRE, Silene de Morais (Org.) Anais do IV Seminário Internacional de Direitos Humanos, violência e pobreza: a situação das crianças e adolescentes na América Latina hoje. Rio de Janeiro: Ed. Rede Sírius/UERJ, 2012.
} 
indivíduos e grupos, especialmente quando se vivem políticas públicas espetáculos, midiatizadas, que levam ao descrédito democrático e tornam a coisa pública um governo de juízes. "A educação para a tolerância e para o respeito do outro é condição necessária à democracia." 59

Essas são contradições identificadas na proposta socioeducativa, mas que permanecem acriticamente e autorizam a aplicação de medidas socioeducativas de internação sem qualquer discussão a respeito. Mas este paradoxo o relatório reconhece:

A Comissão ousa afirmar que, atualmente, a pressão da competição faz com que muitos responsáveis esqueçam a missão de dar a cada ser humano os meios de poder realizar todas as suas oportunidades. Conscientes disto, e no âmbito deste relatório, fomos levados a retomar e a atualizar o conceito de educação ao longo de toda a vida, de modo a conciliar a competição que estimula, a cooperação que reforça e a solidariedade que une ${ }^{60}$.

Não obstante essas considerações, o homem é um ser capaz de assumir-se como sujeito de sua história e da História, agente de transformação de si e do mundo, fonte de iniciativa, liberdade e compromisso nos planos pessoal e social, isto é, deve se reconhecer os adolescentes como sujeitos na vida. Isto é, eles devem construir em sua mente a representação sobre si mesmos e do mundo que fazem parte, desvelando criticamente o sentido de sua presença no mundo e entre os homens, por meio do diálogo, da reflexão conjunta, pois "significar o mundo é assumir diante dele uma atitude de não indiferença, é atribuir-lhe um valor”"61.

Aliás, considerando objetivar a medida socioeducativa a reinserção responsabilizada do adolescente à vida coletiva, deveria pautar-se no sentido de estimulá-lo ao convívio social, integrando-o à coletividade, havendo, portanto, contato frequente com o mundo externo. A liberdade, segundo a concepção que orienta a proposta socioeducativa, não significa a não restrição - "as exigências, as normas, os deveres, e até mesmo as punições são e apresentam para nós como contrário ou negação à liberdade" ${ }^{2}$, mas demanda um posicionamento claro e firme do educador, formando direitos e deveres de cada um dos atores do processo pedagógico.

O caminho do desenvolvimento social é marcado por disciplinamentos internos (não externos, porque configuraria regime de disciplinamento), em que envolve autoconsciência (aceitar-se), autoestima (encontro consigo é a base para o encontro com o outro e para ter valor

\footnotetext{
59 DELORS, Jacques. Educação: um tesouro a descobrir. Relatório para a Unesco da Comissão Internacional sobre Educação para o século XXI. Unesco: MEC, 1996.

${ }^{60}$ Ibid., p. 13.

${ }^{61}$ COSTA, Antônio Carlos Gomes de. Aventura pedagógica. Caminhos e descaminhos de uma ação educativa. São Paulo: Columbus Cultural editora, 1990, p. 54.

${ }^{62}$ Ibid., p. 54.
} 
por si é preciso ter certeza que se teve valor para alguém, numa lógica de espelho existencial), autoconceito (é a autoestima no plano da racionalidade - gostar de si), autoconfiança (ter força em si), autovalorização (visão do próprio futuro), autodeterminação (disciplina), autoproposição (um plano para a vida cuja ausência gera nostalgia para o passado ou fantasia para o futuro) e autopreservação (resiliência) ${ }^{63}$.

No entanto, não é assim. O que existe é material e simbolicamente uma barreira com o mundo externo, cujas saídas são impedidas pela arquitetura e por mecanismos defensáveis ${ }^{64}$.

Ante todas essas considerações, insta ponderar: "O que esperar do tratamento jurídico, protagonizado pelo sistema penal, dirigido aos adolescentes, senão a tendência autoritária em que se crer possível transformar o poder punitivo em direito tutelar?"65

Não cabe aqui (e nem cabe essa questão prioritariamente ao Direito), porém, discutir o que deve ser a medida socioeducativa de internação. Porém, uma coisa é certa - é preciso evitar a padronização e a imposição da sanção educativa pelo medo que a sociedade tem do adolescente, pois isso implica produção de prevenção geral, enquanto fundamento da medida, o que significa uma movimentação esquizofrênica do sistema; pois neste sentido impõe-se o castigo por mera suspeita, imaginando-se que todos são potencialmente culpados e desde logo devem se curvar ao risco de serem punidos ${ }^{66}$. E isso é paradoxal, já que a infração é a normalidade da adolescência.

\section{CONCLUSÃO}

O presente trabalho discutiu a natureza da medida socioeducativa de internação (ontologia) e os objetivos (teleologia) indicados pela legislação da criança e do adolescente para o instituto; tendo como hipótese, a partir do marco teórico crítico adotado, que haveria uma ambiguidade nesse instituto, na medida em que pretende socioeducar a partir da resposta responsabilizatória da prática de um ato infracional.

\footnotetext{
${ }^{63}$ COSTA, Antônio Carlos Gomes (coord). Parâmetros para a formação do socioeducador. Uma proposta inicial para a reflexão e debate. Brasília: Secretaria Especial de Direitos Humanos, 2006, p. 95.

${ }^{64}$ GOFFMAN, Erving. Manicômios, prisões e conventos. São Paulo: Perspectiva, 1987.

${ }^{65}$ FERNANDO NIÑO, Luis. El derecho de los niños y los adolescentes en una sociedade en permanente crisis. In: ZAPATERO, Luis A; TERRADILLOS BASOCO, Juan M; et al. Homenaje ao Dr. Marino Barbero Santos. Cuenca: Ediciones Universidad Salamanca, 2001.

${ }^{66}$ GODWIN, Willian. Investigacion acerca de la Justicia Politica y su inflencia en la virtude y la dicha generales. Buenos Aires: Editorial Americalee, 1945.
} 
Em essência, ante o empirismo da prática socioeducativa, percebeu-se que o discurso socioeducativo, com finalidades de projeção do adolescente para a vida coletiva, é um mecanismo retórico de contenção desse sujeito quando não se adequa aos padrões do que se considera juventude normal.

Do ponto de vista ontológico, a medida é de fato retributiva, dado que é a resposta estatal face à prática infracional. Porém, na medida em que se reconhece ser a medida socioeducativa de internação retributiva, não se quer aqui afirmar que pode ser confundida com pena, ao reverso. Apresentou-se, ao longo do texto, que, devido à condição peculiar de desenvolvimento, não pode a medida comportar os mesmos objetivos da pena.

Isto é, não cabe à pretensão de prevenção geral, vez que o adolescente não pode ser manipulado para fins específicos que não digam respeito à sua própria vida (não pode ser objeto para fins utilitaristas). Além disso, a perspectiva de prevenção especial é irrealizável. Já restou evidente ao longo da história que qualquer pretensão ressocializadora, além de padronizar o sujeito que a ela está submetido, viola sua autonomia moral. E mais, o confinamento em si, para funcionar como punição, deve produzir o padrão de less elegibility - a vida na prisão é pior do que a pior situação fora da prisão. Do fim ao cabo isso significaria dizer que a internação seria destinada a marginalizar o adolescente que nela está incluído, já que a marginalidade social é um dos piores cenários da realidade brasileira. O fim retributivo, portanto, é, por uma operação lógica, incompatível com a proposta socioeducativa.

De outra banda, a teleologia da medida socioeducativa de internação não é de educação formal, mas uma educação voltada à emancipação do adolescente, conscientizando-o de valores sociais. O Sinase e o PIA seriam instrumentos garantidores da construção de um projeto individual para esse crescimento do adolescente.

Esse objetivo implica confiança no adolescente, protagonismo, inclusive político, de defesa de direitos, acesso a informações, etc., não devendo ser o PIA mero instrumento burocrático de comunicação entre Judiciário - Ministério Público - Executivo. Como compatibilizar essa pretensão ao confinamento? Cujo pressuposto é a grade que simboliza exatamente a ausência de confiança. Não é possível, portanto, admitir, ainda que teoricamente, que a socioeducação seja capaz de emancipar o adolescente, trazendo-o para a vida na coletividade transformado de seus valores, internalizando a cultura social.

Assim, como demonstrado, cultura não se modifica pela lei; logo, a socioeducação na internação (apesar de não ser possível ao Direito por si só pensar sobre ela) é uma estratégia 
retórica de manipulação do poder punitivo. Esse raciocínio é evidente no Sinase - uma lei que regula a execução da medida socioeducativa.

É preciso então evitar eufemismos, ingenuidades e até mesmo cinismos. É preciso reconhecer que a medida socioeducativa é punitiva (que não poderia ser) e que a socioeducação é um conceito em aberto, sendo incapaz o Direito de defini-la. Cabe ao Direito respeitar o que não pode ser a socioeducação: pena. Isto é, não pode a socioeducação pretender realizar prevenção geral e especial.

Se os juristas ao aplicarem a medida socioeducativa de internação creem projetar formas de emancipação, é preciso que se conscientize que não se emancipa desconfiando do sujeito, por isso deve permanecer confinado da vida coletiva para o qual, mais tarde, voltará. Portanto, antes de pensar exageradamente sobre medida socioeducativa de internação como forma de punição do adolescente, é melhor realizar um esforço maior que não retribua o mal causado pelo adolescente, quando pratica um ato infracional, mas que promova cidadania juvenil.

\section{REFERÊNCIAS}

ABERASTURY, Arminda; KNOBEL, Maurício. Adolescência normal: um enfoque psicanalítico. 5 ed. Porto Alegre, 1986.

ALBRECHT, El Derecho penal de menores, traducción de la primera edición alemana por Bustos Ramírez, Barcelona, 1990.

BARATTA, Alessandro. Elementos de um nuevo derecho para la infância y la adolescência, Capítulo criminológico, v. 23, n. 1. Maracaibo, enero/junio, 1995.

BELOFF, Mary. Los Jóvens y el Delito: La responsabilidad es la clave. In: MÉNDEZ, Emilio García (org.). Infancia Y Democracia en la Argentina. La cuestión de la responsabilidad penal de los adolescentes. Buenos Aires: Del Signo, 2004.

BERNSTEIN, Basil. Clasificacion y enmarcacion del conocimiento educativo. Class, Codes and control, Vol. 1 Towards a Theory of Educational Transmissions London: Routledge and Kegan Paul. 1974.

BRASIL. Lei 12.594. Brasília: Senado Federal, 2012 Disponível em: <http://www.planalto.gov.br/ccivil_03/_ato2011-2014/2012/lei//12594.htm>. Acesso em: 08 ago. 2016.

BRASIL. Lei 9.394. Brasília: Senado Federal: 1996. Disponível em: <http://www.planalto.gov.br/ccivil_03/Leis/L9394.htm>. Acesso em: 08 ago. 2016. 
CAHN, Raymond. 0 adolescente na psicanálise: a aventura da subjetivação. Rio de Janeiro: Companhia de Freud, 1999.

CASTRO, Lola Aniyar. O regresso triunfante de Darwin e Lombroso: as diferenças humanas na Criminologia dos países de língua inglesa anos Simpósios Internacionais de Criminologia de Estocolmo. Discursos Sediciosos. Crime, direitos e sociedade. Ano 15, n. 17/18, p. 163-174,1 e 2 semestres, Rio de Janeiro, Revan, 2010.

CERQUEIRA, Thales Tácito de Pádua. Manual do Estatuto da Criança e do Adolescente: Teoria e Prática. 2 ed. São Paulo: Impetus, 2011.

CILLERO BRUÑOL, Miguel. El Interés Superior del Niño en el Marco de la Convención Internacional sobre los Derechos del Niño. In: UNICEF, Justicia y derechos del niño. Santiago de Chile, 1999.

COSTA, Antônio Carlos Gomes (coord). Parâmetros para a formação do socioeducador. Uma proposta inicial para a reflexão e debate. Brasília: Secretaria Especial de Direitos Humanos, 2006.

COSTA, Antônio Carlos Gomes da. Aventura Pedagógica. Caminhos e descaminhos de uma ação socioeducativa. São Paulo: Columbus Cultural Editoria, 1990.

COSTA, Antônio Carlos Gomes da. In: CURY, Munir, et all (coord.). Estatuto da Criança e do Adolescente comentado: comentários jurídicos e sociais. 3 ed. São Paulo: Malheiros, 2000.

COUSO SALAS, Jaime. Problemas teóricos y prácticos del principio de separación de medidas y programas, entre la vía penal-juvenil y la vía de protección especial de derechos. In: Justicia y Derechos del niño. Santiago: UNICEF, 1999.

COUSO, Jaime. Principio educativo y (re) socialización en el derecho penal juvenile. In: UNICEF. Justicia y derechos del niño. n 8. Chile, 2006.

DELORS, Jacques. Educação: um tesouro a descobrir. Relatório para a Unesco da Comissão Internacional sobre Educação para o século XXI. Unesco: MEC, 1996.

DOLINGER, Jacob. Direito Internacional Privado: a criança no direito internacional privado. Rio de Janeiro: Renovar, 2003.

ELIAS, Roberto João. Comentários Ao Estatuto da Criança e do Adolescente. 4 ed. São Paulo: Saraiva, 2010.

FERNANDO NIÑO, Luis. El derecho de los niños y los adolescentes en una sociedade en permanente crisis. In: ZAPATERO, Luis A; TERRADILLOS BASOCO, Juan M; et al. Homenaje ao Dr. Marino Barbero Santos. Cuenca: Ediciones Universidad Salamanca, 2001.

FERRETI, Celso João. A pedagogia das competências: autonomia ou adaptação? Educação Social, Campinas, v. 23, n. 81, p. 299-306, dez, 2002.

Fórum Brasileiro de Segurança Pública. $9^{\circ}$ Anuário Brasileiro de Segurança Pública. São Paulo, 2015. 
GALUCH, Maria Terezinha Bellanda. Reflexões sobre a organização do ensino e Formação no context das relações sociais de produção. Revista Internacional d'Humanitats, Universitat Autònoma de Barcelona, n. 21, jan-jun, 2011.

GARCÍA MÉNDEZ, Emílio. Infância: de los derechos y de la justicia. 2 ed. Buenos Aires: Editores del Puerto, 2004.

GARCÍA MENDÉZ, Emílio. Prehistoria e historia del control socio-penal de la infancia: política jurídica y derechos humanos En américa latina. In: Ser niño en America Latina. De las necessidades a los derechos. Galerna: Unicri, 1991.

GARLAD, David. A cultura do controle. Crime e ordem social na sociedade contemporânea. Rio de Janeiro: Revan, 2008.

GODWIN, Willian. Investigacion acerca de la Justicia Politica y su inflencia en la virtude y la dicha generales. Buenos Aires: Editorial Americalee, 1945.

GOFFMAN, Erving. Manicômios, prisões e conventos. São Paulo: Perspectiva, 1987.

GURAKH, Soeli Andrea. A socioeducação na dinâmica de afirmação dos direitos da criança e do adolescente no Brasil. Emancipação, 10 (1), p. 351-359, Ponta Grossa, 2010.

ISHIDA, Válter Kenji. Estatuto da Criança e do Adolescente. São Paulo: Atlas, 2014.

KONZEN, Afonso Armando. Pertinência Socioeducativa: Reflexões sobre a natureza jurídica das medidas. Porto Alegre: Livraria do Advogado, 2005.

MARTINSON, Robert. What Works? - questions and answers about prison reform. Disponível em < <http://www.nationalaffairs.com/doclib/20080527_197403502whatworksquestionsandanswersab outprisonreformrobertmartinson.pdf >. Acesso em: 04 ago. 2016.

MELOSSI, Darío. Ideología y Derecho Penal. Garantismo Jurídico y criminologia crítica: ?Nuevas ideologías de la subordinacíon? Revista Nueva Doctrina Penal. Buenos Aires, p. 75-86, Del Porto Ed, 1996.

MENDÉZ, Emilio García. Infância e cidadania na América Latina. São Paulo: Hucitec, 1998.

MOREIRA, Celeste Anunciata Baptista Dias. Socioeducação e as medidas socioeducativas. In: FREIRE, Silene de Morais (Org.) Anais do IV Seminário Internacional de Direitos Humanos, violência e pobreza: a situação das crianças e adolescentes na América Latina hoje. Rio de Janeiro: Ed. Rede Sírius/UERJ, 2012.

$\mathrm{NUCCl}$, Guilherme de Souza. Estatuto da Criança e do Adolescente Comentado. 2 ed. São Paulo: Forense, 2014.

ONU. Regras Mínimas das Nações Unidas para a Administração da Justiça, da Infância e da Juventude. Regras Mínimas de Beijing. Disponível em

<http://www.crianca.caop.mp.pr.gov.br/arquivos/File/politica_socioeducativa/regras_minimas _beijing.pdf>. Acesso em: 12 out. 2015.

OTERO, Juan Manuel. A hipocrisia e a dor no sistema de sanções do direito penal, Discursos Sediciosos, crime, direito e sociedade, Rio de Janeiro, 2007. 
ROXIN, Claus. Estudos de Direito Penal. 2 ed. Rio de Janeiro: Renovar, 2008.

RUSCHE, George; KIRCHHEIMER, Otto. Pena y estructura social. Bogotá: Temis, 1984.

SÊDA, Edson. Os eufemistas e as crianças no Brasil. Rio de Janeiro: Adês, 1999.

SOARES, L. E. Cabeça de Porco. Rio de Janeiro: Objetiva, 2005.

SPOSATO, Karyna. Guia Teórico e prático das medidas socioeducativas. ILANUD/UNICEF. Brasília, 2004.

UNICEF - Fundo das Nações Unidas para a Infância. Relatório. Situação Mundial da Infância. Adolescência, uma fase de oportunidades, 2011.

Recebido em: 12/10/2015 / Revisões requeridas em: 21/07/2016 / Aprovado em: 16/08/2016 